\title{
Clóvis Luiz Machado-da-Silva e o Observatório
}

\author{
Marcelo Milano Falcão Vieira ${ }^{1}$ \\ Cristina Amélia Carvalho ${ }^{2}$ \\ Eloise Helena L. Dellagnelo ${ }^{3}$ \\ Rosimeri Carvalho da Silva ${ }^{4}$
}

O grupo de pesquisa Observatório da Realidade Organizacional manifesta seu reconhecimento ao Professor Clóvis L. Machado-da-Silva. A contribuição do Professor Clóvis aos estudos e pesquisas em administração foi relevante, bem como sua participação em atividades acadêmicas, quer como professor, pesquisador e administrador. Teve também atuação proativa no CNPq, na ANPAD e em outras instituições voltadas para a área da administração. Particularmente foi como Professor do curso de Pós-Graduação em Administração da Universidade Federal de Santa Catarina (CPGA/UFSC) e Coordenador do Núcleo de Análise, Planejamento e Pesquisa em Organizações (NAPPO) que tivemos a oportunidade de receber do Professor Clóvis ensinamentos, orientação e especialmente a formação metodológica sólida tão fundamental nas etapas que se seguiram em nossa trajetória profissional. Tanto no ensino como nas atividades de pesquisa, o Professor Clóvis sempre demonstrou zelo na orientação metodológica de seus alunos e iniciantes no desenvolvimento de projetos de pesquisa.

Muitos membros do Observatório da Realidade Organizacional foram seus alunos, participantes em projetos de pesquisa do NAPPO e orientados em dissertações de mestrado e tese de doutorado. Todos guardamos do Professor Clóvis a imagem do profissional dedicado à formação qualificada dos jovens que optaram pela área da administração. Tinha o senso da responsabilidade com a produção científica como forma de evolução dos métodos de inovação na prática da administração. Independente de posições conceituais eventualmente divergentes, reconhecemos o quanto o Professor Clóvis foi importante em nossa formação e na contribuição que deixou como mestre e pesquisador no campo do conhecimento em administração.

Expressamos o nosso pesar pela lacuna deixada pelo Professor Clóvis e manifestamos nossa gratidão pelos ensinamentos que nos proporcionou.

\footnotetext{
${ }^{1}$ Professor de Estudos Organizacionais na EBAPE/FGV. Coordenador da unidade Rio de Janeiro do grupo de pesquisa Observtório da Realidade Organizacional. PhD. em Administração pela University of Edinburgh, Escócia. Mestre em Administração Pública pelo CPGA/UFSC. Pesquisador do CNPq. EBAPE/FGV - Praia de Botafogo, 190 - sala 530 / CEP: 22250-900 - Rio de Janeiro, RJ - Brasil / Tel. (21) 3799-5747; E-mail: marcelo.vieira@fgv.br .

${ }^{2}$ Professora de Estudos Organizacionais na Escola de Administração da Universidade Federal do Rio Grande do Sul. Pesquisadora do grupo de pesquisa Observatório da Realidade Organizacional na unidade de Porto Alegre. Doutora em Ciências Econômicas e Empresariais pela Universidad de Cordoba, Espanha. Mestre em Administração pelo CPGA/UFSC. Pesquisadora do CNPq. UFRGS - Rua Washington Luiz, 855 - Centro / CEP: $90010-460$ - Porto Alegre, RS - Brasil / Tel. (51) 33083860 ; E-mail: cris carvalho@uol.com.br .

${ }^{3}$ Professora de Estudos Organizacionais na Universidade Federal de Santa Catarina. Coordenadora da unidade de Florianópolis do grupo de pesquisa Observatório da Realidade Organizacional. Doutora em Engenharia da Produção pela Universidade Federal de Santa Catarina. Mestre em Administração pelo CPGA/UFSC. Pesquisadora do CNPq. UFSC - Centro Sócio-Econômico, Departamento de Ciências da Administração/Campus Universitário - Trindade 88040-900 - Florianopolis, SC - Brasil / Tel. (48) 37219365 ; E-mail: eloise@cse.ufsc.br .

${ }^{4}$ Professora de Estudos Organizacionais na Escola de Administração da Universidade Federal do Rio Grande do Sul. Coordenadora da unidade de Porto Alegre do grupo de pesquisa Observatório da Realidade Organizacional. Doutora em Administração pela HEC-Paris. Mestre em Administração pelo CPGA/UFSC. UFRGS - Rua Washington Luiz, 855 - Centro / CEP: 90010-460 - Porto Alegre, RS - Brasil / Tel. (51) 33083861 Pesquisadora do CNPq; E-mail: rfcsilva@ea.ufrgs.br.
} 